BRANDT, Line. The communicative mind: a linguistic exploration of conceptual integration and meaning construction. Newcastle upon Tyne: Cambridge Scholars, 2013. $636 \mathrm{p}$.

\title{
A mente comunicativa: uma análise linguística da integração conceptual e da construção de sentidos
}

\author{
Josiane Militão*
}

A investigação linguística tem se pautado pela necessidade de levar em conta, em suas concepções teóricas e metodológicas, a dimensão multifacetada de seu objeto. A complexidade da linguagem, como um fenômeno do mundo natural, em que estão em jogo aspectos fenomenológicos, biológicos, psíquicos, cognitivos e sociais de um sujeito que a constrói e que nela se constrói para viver, exige do linguista a tarefa de, em seu trabalho investigativo, dialogar com outras áreas do conhecimento.

Com a preocupação de considerar o sujeito e, principalmente, a "harmonização com o outro" como o cerne da linguagem, Line Brandt investiga, em uma perspectiva interdisciplinar, a subjetividade na enunciação, com ênfase no processo de construção de sentidos, na estruturação e na troca de signos linguísticos. Nessa perspectiva, a pesquisadora entende que linguagem e cognição estão inerentemente imbricadas no intercâmbio das interações discursivas, em que um enunciador se dirige a um enunciatário ao compartilhar mutuamente a atenção. Brandt instaura seus estudos na área da Semiótica Cognitiva e neles incorpora o paradigma das Ciências Cognitivas das últimas décadas: o fato de que a cognição humana é fundamentalmente social.

A obra The communicative mind: a linguistic exploration of conceptual integration and meaning construction, lançada por Line Brandt pela Cambridge Scholars, em 2013, explora várias formas de manifestação da subjetividade na enunciação por meio de uma pesquisa que articula Ciências Cognitivas, Filosofia, Psicologia, Fenomenologia, Linguística, Semiótica e Estudos Literários.

\footnotetext{
* Pontifícia Universidade Católica de Minas Gerais (PUC Minas). Texto vinculado ao Projeto: Uma visão integrada da cognição humana: corpo/significação, cérebro, mente e linguagem, financiado pela FAPEMIG (SHA APQ 00121/10).
} 
Brandt deixa claro que não há como analisar a linguagem sem levar em conta sua dimensão fenomenológica e traz significativa contribuição ao utilizar dados naturais em suas análises (instâncias de uso da linguagem, oral e escrita, literária e não literária), opção não muito comum nas pesquisas em Linguística Cognitiva. Essa escolha requer um estudo sob um olhar multidisciplinar, mas seu percurso acadêmico lhe permite e lhe autoriza examinar e articular pressupostos teóricometodológicos de áreas as mais diversas, o que faz com posicionamento crítico e rigorosa preocupação científica.

Line Brandt é doutora em Semiótica Cognitiva pela Universidade de Aarhus, na Dinamarca, e mestre em Filosofia e Inglês. Pesquisadora, professora, editora de obras literárias e acadêmicas, é também tradutora de textos da área de Teoria da Literatura e de textos literários, incluindo-se a Poesia Cognitiva. Suas pesquisas acadêmicas concentram-se, por outro lado, em Linguística Cognitiva, Semiótica Cognitiva e Filosofia.

The communicative mind é uma obra de fôlego, resultante de extensa e cuidadosa pesquisa de doutoramento da autora, realizada na Universidade de Aarhus sob a orientação de Steven Ostergaard, finalizada em 2010. A extensão e o esmero da pesquisa são revelados não somente pelo volume da obra (636 páginas), mas também pela cuidadosa atenção dada aos conceitos, pressupostos ou premissas que compõem e/ou subjazem a seus estudos. A linguista os explora por meio de uma análise, por vezes diacronicamente organizada, das pesquisas publicadas sobre o assunto, em várias áreas do conhecimento. Ora no corpo do texto, ora em longas notas de rodapé, preocupa-se em descrever e comparar as premissas básicas de cada abordagem, na medida em que colaboram ou se opõem aos conceitos ou pressupostos assumidos em sua pesquisa.

O livro estrutura-se em quatro partes, que podem ser lidas em sequência ou separadamente. Na primeira, a autora apresenta os propósitos do trabalho e trata da enunciação e dos aspectos da subjetividade na construção dos significados. Na segunda, da interação fictiva por via de uma retomada crítica da Teoria da Integração Conceptual - TIC - (FAUCONNIER; TURNER, 2002) e, a partir dela, apresenta um modelo de integração conceptual que descreve o processo de construção de sentidos em uma perspectiva semiótica. Na terceira e última parte, a pesquisadora preocupa-se em aplicar o modelo semiótico de integração conceptual na análise da construção de sentidos no texto literário e também em analisar estratégias enunciativas utilizadas na poesia cognitiva, ao que denomina enunciação poética. 
$\mathrm{Na}$ introdução do livro, a autora apresenta os fundamentos de sua pesquisa e seus pressupostos teóricos e metodológicos, descrevendo os parâmetros a partir dos quais irá desenvolver seu trabalho: as premissas básicas da Semiótica Cognitiva, descritas pelo Grupo de Semiótica Cognitiva da Universidade de Aarhus, fundado em 2001 por Per Aage Brandt ${ }^{1}$ e vários colaboradores.

Nesse primeiro momento, Line Brandt promete elaborar uma metodologia analítica que considera fatores pragmáticos da enunciação e da produção de enunciados como características nucleares da linguagem e como fundamentais para a teorização e a análise linguística (BRANT, 2013, p. 3). Ressalta os benefícios de analisar unidades de significados em seu contexto retórico e de trabalhar preferencialmente com dados naturais.

A pesquisadora retoma vários autores que orientam seus estudos pela dimensão social da linguagem para justificar suas escolhas e dá especial voz a Benveniste, ao abordar a presença do homem na linguagem. Para Brandt, a função referencial da linguagem parece ser secundária à ação enunciativa de se dirigir a outra pessoa: no cerne da linguagem está a harmonização com o outro (BRANDT, 2013, p. 5).

Brandt admite que essa premissa impõe aos pesquisadores da linguagem uma série de desafios a crenças amplamente aceitas, como a da primazia do domínio físico para a produção de sentidos. A semioticista finaliza essa parte introdutória da obra reforçando o foco e o objetivo de seu trabalho, que é esclarecer o papel da fictividade (fictivity), ou não realidade (non-actuality), na representação e identificar diversos aspectos da subjetividade na produção de sentidos como manifestações linguísticas de mentes que interagem.

Se, por um lado, o leitor de The communicative mind é brindado com o tratamento de variadas facetas da produção de sentidos, como aponta a autora, ressente-se, por outro lado, da falta de uma maior articulação entre os diversos objetos apresentados para estudo (subjetividade, enunciação, fictividade, enunciação poética). Considerar o fenômeno linguístico em sua complexidade é um mérito, mas o leitor mais atento e que se interessa pela obra como um todo pode buscar uma maior correlação entre as análises realizadas. A obra se revela mais como resultado de um programa de pesquisa do que de uma pesquisa de doutoramento propriamente dita. Ao que parece, identificam-se três pesquisas naquela que é apresentada como única: uma sobre a fictividade, outra sobre a integração conceptual (sua aplicação à análise de textos literários) e outra sobre a enunciação poética naquilo que denomina poesia cognitiva. Obviamente todas

1 Line Brandt faz várias referências aos trabalhos do pai, o semioticista Per Aage Brandt. Para fins de distinção, doravante Per Aage Brandt será referido como "P. A. Brandt", e Line Brandt, como "Brandt". 
estão inscritas em uma perspectiva que busca revelar a marcante presença da (inter)subjetividade no processo de produção de sentidos decorrente da interação enunciativa, o que parece ser o fio condutor que as tece em uma coerência argumentativa.

Na primeira parte da obra, em um capítulo único, são descritos os aspectos da subjetividade na construção do significado no discurso sob a ótica da Teoria da Enunciação, de Benveniste (1971). Brandt faz uma introdução à enunciação e uma discussão sobre sua relevância para os estudos linguísticos e literários. A linguista estabelece uma relação entre a enunciação e várias formas de uso criativo da linguagem, identificando traços de subjetividade de mentes interactantes na ficção, na poesia e na criatividade do dia a dia, sempre atenta à coerência de seu método de análise, que é sensível tanto a aspectos do uso da língua como à articulação entre semântica e conceptualização.

A enunciação é, na obra, tratada como "ato individual de produção da linguagem, em um dado contexto situacional, que se manifesta estruturalmente e pragmaticamente carregado de intenções e cujo significado é dependente da interação" (BRANDT, 2013, p. 47). A enunciação está sempre inscrita em uma subjetividade particular, e é sempre um ato desempenhado por um falante que estabelece relação com outro, ou seja, a subjetividade é inerente à gramaticalização.

A autora busca demonstrar marcas da subjetividade manifestadas em aspectos enunciativos da interação discursiva. Subjetividade, para ela, em consonância com Benveniste é: "a capacidade do falante de se posicionar como um "sujeito" (BENVENISTE, 1971, p. 224) e se diferencia do ponto de vista, que é "o enquadramento que a subjetividade da mente realiza de conteúdo proposicional, implícito ou explícito" (BRANDT, 2013, p. 63). Na enunciação estão em jogo vários pontos de vista encaixados.

A partir dessas definições e, utilizando a tipologia de pontos de vista baseada em forças epistêmicas e experienciais (BRANDT, 2004), a pesquisadora faz um pequeno exercício de análise para ilustrar como vários pontos de vista podem estar relacionados em uma situação de enunciação. Line Brandt discorda da convergência estabelecida por P. A. Brandt entre os conceitos de enunciação e de ponto de vista e também questiona a regularidade da relação proporcionalmente inversa que ele apresenta entre a força experiencial (subjetiva) e a epistêmica (objetiva). Além disso, desconfia, na tipologia proposta por P. A. Brandt, da natureza do "ponto de vista olímpico". Na perspectiva adotada por Line Brandt, voltada para o sujeito, para a subjetividade, não se pode sequer cogitar a possibilidade de atribuir um status de verdade inquestionável a um ponto de vista. A semioticista propõe que este seja 
considerado o "ponto de vista de ninguém", impessoal, mas sempre inscrito no ponto de vista editorial de um sujeito enunciador de primeira pessoa, uma subjetividade outra que não a do falante.

Assumindo a perspectiva de que a licença poética permite que a enunciação ficcional se diferencie bastante do endereçamento e da força epistêmica "comuns" na voz do narrador onisciente (BRANDT, 2013, p. 77), Brandt analisa a enunciação encaixada (embedded enunciation). A partir daí, descreve o sujeito editorial, que é aquele que organiza os significados, sem participar de sua construção, sem experienciá-los, mas que se constitui em um "eu" da enunciação. Busca em Talmy (2000) a noção de endereçamento para esclarecer essa função do sujeito editorial. Quer seja na enunciação natural quer na literária, o sujeito editorial é aquele "sujeito enunciativo, singular ou plural, que é a fonte em que se encaixam todos os outros pontos de vista. (...)" (BRANDT, 2013, p. 88). Conclui esse primeiro capítulo com a conviç̧ão de que a interação intersubjetiva é primária e fundamental para a linguagem e de que a função referencial, embora seja um componente crucial, é secundária à reciprocidade comunicativa.

A segunda parte, a mais extensa de todas, é subdividida em dois capítulos. O primeiro deles, capítulo dois, é dedicado a uma crítica à abordagem da Linguística Cognitiva ao fenômeno da interação fictiva, "tipicamente manifestada na forma de um enunciado imaginado cuja 'não realidade' (non-actuality) é marcada gramaticalmente e acompanhada, na língua falada, por alterações entoacionais e outros índices gestuais expressivos" (BRANDT, 2014, p. 116). Nas construções fictivas, utilizamos a dramatização como uma importante estratégia representacional. Para a pesquisadora, do ponto de vista semiótico-cognitivo, o único tipo de fictividade relevante é a fictividade representada: "fictividade do ponto de vista de um conceptualizador ou de um grupo de conceptualizadores que se comunicam (BRANDT, 2013, p. 130)." Os interactantes representam os fatos como se fossem reais, as entidades na fictividade são específicas, mas são revestidas de uma descrença por parte do enunciador.

Brandt baseia-se em Pascual (2006) para analisar o fenômeno da interação fictiva, já que seus estudos revelam um quadro teórico bastante compatível com a abordagem semiótica. Aponta, porém, duas distinções entre sua proposta e a de Pascual: i) uma distinção de natureza conceitual, porque a semioticista diferencia enunciação pessoal (ligada a um sujeito específico) de enunciação genérica (o enunciador é apresentado de forma genérica, sem especificação); ii) outra, mais importante, de natureza ontológica e, portanto, metodológica. Para ela, a TIC e a noção de espaços mentais não são tão úteis para analisar o fenômeno, como considera o pesquisador 
(BRANDT, 2013, p. 108). Para Brandt, a operação de integração conceptual não é a melhor forma de explicar a interação fictiva representada metonimicamente, como considera Pascual (2006). Por outro lado, para análises que considerem a integração semiótica, a teoria se mostra vantajosa porque possibilita, do ponto de vista cognitivo, representar o fenômeno da interação fictiva de maneira clara por meio de diagramas.

Neste ponto julgo importante ressaltar uma opção teórico-metodológica da autora, que não se acanha em percorrer diversos quadros teóricos, criticá-los, descrever suas potencialidades e fragilidades para a análise do objeto em questão, e aplicar os pressupostos teóricos e metodológicos mais profícuos para suas análises. Brandt relativiza a aplicação de um dos princípios básicos da Teoria da Integração Conceptual, que é exatamente o pressuposto de que todo processo de produção de sentidos dá-se por meio da operação básica de integração conceptual, fatorada nas operações de identidade, integração e imaginação. Fauconnier e Turner as descrevem como "básicas, misteriosas, poderosas, complexas e quase sempre inconscientes e estão no cerne do significado mais simples possível" (FAUCONNIER; TURNER, 2002, p. 6). Assim, todo e qualquer processo de produção de sentidos pode e deve ser explicado por meio da integração conceptual, inclusive a interação fictiva por via da metonímia. Relativizar a aplicação desse princípio que, segundo os próprios autores, é a chave para todo e qualquer processo de produção de sentidos requer, no mínimo, que tenhamos argumentos filosófica, semiótica e linguisticamente bastante fortes e convincentes, e Line Brandt realiza esse movimento com muita competência e rigor, apontando a quebra de paradigma dos trabalhos de Talmy e Langacker, em particular, que colocaram em cena o sujeito conceptualizador. Distingue os diferentes usos de fictividade, descritos por esses pesquisadores, e conclui que os efeitos da subjetividade humana são ubíquos na linguagem, e a virtualidade é fonte básica e fundamental na representação. A fictividade é um fenômeno de subjetividade, centrado no conceptualizador que enuncia, e o mais notável é o engajamento natural, sem esforço, da cognição virtual na construção do significado.

O capítulo seguinte, número três, é considerado pela autora "um livro dentro do livro". Isso porque pode ser lido de maneira isolada pelo leitor interessado na Teoria da Integração Conceptual, proposta por Fauconnier e Turner (2002). Ainda analisando o fenômeno da interação fictiva, Brandt faz uma crítica bastante contundente à TIC ao colocar em debate seu escopo e a aplicabilidade de suas premissas básicas, incorporando a esta noções de Semiótica (estrutura dos signos) e da Teoria da Enunciação (instância enunciativa), que considera indispensáveis aos estudos do significado na comunicação humana e discutindo as implicações teóricas 
dessa incorporação. Com o estudo da relação entre premissas desses quadros teóricos, pretende entender o papel da subjetividade na representação e identificar maneiras pelas quais o sujeito da enunciação se manifesta nos enunciados.

Ao tratar da abrangência e da propriedade das análises realizadas na Teoria da Integração Conceptual, a semioticista apresenta suas potencialidades. Pondera que, apesar de partir de uma visão tradicional da semântica, que "localiza o significado fora da mente humana" (BRANDT, 2013, p. 200), Fauconnier (1994), ao definir espaços mentais, acentua o lugar natural de suas configurações no discurso. Embora sejam realizadas análises lógicas e descritivas de sentenças por vezes descontextualizadas, a TIC foi projetada para lidar com fenômenos naturais da linguagem. Segundo a linguista, a teoria constitui-se em fonte de inspiração para estudos de objetos de campos os mais diversos, como a computação, a matemática, os estudos jurídicos, os estudos da linguagem de sinais, da tecnologia, da religião, do humor, da música e da criatividade literária. A vantagem da TIC, segundo Brandt, é que ela é profícua para entender os processos cognitivos da interpretação semântica sem invocar a lógica reversa como um fator para explicar o significado interpretado, que não dá conta de fenômenos como a metáfora, por exemplo.

Por outro lado, para ela, nesse quadro teórico, as noções básicas são dadas como aceitas, sem uma descrição de prós ou contras de sua aplicação para análise de fenômenos específicos. Somado a isso, os termos são aplicados de maneira abrangente, como que para prevenir uma apreensão clara de seu significado, e, consequentemente, evitar um questionamento sobre sua eficácia no avanço da compreensão científica. Isso vale, segundo ela, infelizmente, também para a noção de "integração conceptual" (BRANDT, 2013, p. 324). Nesse sentido, como se pode perceber, de maneira corajosa e altiva, a pesquisadora não poupa críticas à teoria, discutindo seus pressupostos filosóficos. Elejo aqui aquelas que considero mais marcantes e que inovam ao proporem uma releitura dos princípios básicos da TIC.

Para Brandt, não estão claros os critérios pelos quais construímos os espaços mentais. A noção de space builder (construtor de espaço), proposta por Fauconnier e Turner, apoiada em elementos linguísticos formais, não a convence, pois, segundo ela, não se consideraram, de maneira sistemática, os vários aspectos relevantes para a organização conceptual que nos levam a construir espaços (principalmente os pragmáticos, situacionais). Nesse sentido, há dificuldades para se determinar o conteúdo dos espaços. A determinação de parâmetros para a "escolha" do conteúdo dos espaços é absolutamente necessária, pois é improvável que fôssemos capazes de nos comunicar se a estrutura dos espaços variasse radicalmente de falante para falante. 
Além disso, o pressuposto de que há uma propensão para a propagação descontrolada de espaços parece, em sua perspectiva, problemática, tanto do ponto de vista filosófico quanto prático, metodológico (BRANDT, 2013, p. 212). Isso porque os autores propõem a categorização dos espaços em termos de representações mentais (em uma perspectiva cognitiva) ou de construções de mundo (em uma perspectiva da semântica analítica) em que essas se tornam mais ou menos equiparadas a funções simbólicas. A pesquisadora admite que a solução para esse problema não é simples e gera outra questão, que é "quando nós verdadeiramente precisamos de espaços mentais?” (BRANDT, 2013, p. 213).

Essas questões nos levam a outras, cruciais para a teoria, cujas respostas Line Brandt busca, como sempre, ao percorrer um longo caminho entre outras abordagens que consideraram o assunto: o que é um espaço mental? Como podemos discernir a estrutura dos espaços? Qual a natureza do significado que está sendo construído?

Brandt opta por sustentar suas argumentações para corroborar ou questionar a TIC em análises nos exemplos clássicos ${ }^{2}$ (principalmente metafóricos) de Fauconnier e Turner (2002). Com esse mesmo propósito, procura estudar as premissas da TIC com base em análises realizadas em diversos outros quadros teóricos, sejam eles do campo da Linguística Cognitiva (Lakoff; Johnson, Coulson, Sweetser), da Semiótica Cognitiva (P. A. Brandt, Talmy, Oakley), da Gramática de Construções e Stemática (Goldberg, P. A. Brandt), da Semiótica (Bundgaard), da Psicologia e Neurociência (Pöppel, Gibbs).

A partir dessas críticas, e tomando o modelo da integração conceptual de Fauconnier e Turner como ponto de partida, Brandt apresenta o modelo semiótico de integração conceptual do grupo de semiótica cognitiva da Universidade de Aarhus. Esse modelo é apresentado como uma alternativa que busca minimizar os problemas apontados, na medida em que tem uma orientação pragmática, sensível ao contexto e que incorpora análises específicas da produção de significados em seu contexto situacional de enunciação, além de permitir distinção entre a integração conceptual de signos de outros tipos de integração.

O modelo semiótico de integração conceptual prevê uma rede composta por, no mínimo, seis espaços, que podem ser de natureza ontológica ou semiótica. Segundo a pesquisadora, o espaço-base é aquele em que acontece a enunciação e em que se produzem os sentidos, noção mais próxima da noção de ground de Langacker (1999). Esse espaço é a base para a construção de todos os outros (apresentação, referência, blend, relevância e efeito de sentido).

2 A metáfora do "cirurgião e do açougueiro", "cavar a própria cova" e do "papa boxeador". 
Fenomenologicamente falando, ao se comunicarem, as pessoas representam a situação de enunciação, e essa representação compartilhada é um pré-requisito para a construção do significado em um fenomundo em que tudo pode servir de objetos de pensamento, independentemente de sua possibilidade de existência fora da mente dos cognoscentes.

Na TIC, o que está sendo enunciado e como está sendo enunciado não são parâmetros para a construção de espaços de input, que podem ser múltiplos, aspecto veementemente criticado por Brandt, como vimos. Os espaços, na TIC, têm uma característica mais conceitual, tópica, do que discursiva.

Brandt conclui que o modelo semiótico de integração conceptual reflete o fato de que blends semióticos (em que um input se torna signo para outro) são construídos online e são sensíveis ao contexto, tanto em relação a como o conteúdo dos inputs é construído quanto à relevância semântica e pragmática da integração desses inputs. Ressalta esse aspecto por considerar que, na TIC, o significado não está ancorado em uma semiose, em uma instância enunciativa, mas no mundo mental privado de um conceptualizador. A ideia é chamar a atenção para o fato de que a reflexão fenomenológica sobre a construção de sentidos é indispensável para a análise semântica.

$\mathrm{Na}$ terceira e última parte, igualmente subdividida em dois capítulos, a semioticista enfatiza o objeto estético e busca aplicar o modelo semiótico de integração conceptual a análises de textos literários.

No capítulo quatro, busca correlacionar estratégias enunciativas empregadas em textos literários ao modelo semiótico da TIC para desvelar as construções semânticas intricadas, por exemplo, em uma instância do pensamento contrafactual. No capítulo cinco, o mais breve de todos, Brandt volta sua atenção para o que denomina enunciação versificada, não natural, e explora aspectos semânticos, sintáticos, fonéticos, rítmicos e retóricos da iconicidade semiótica (semiotic iconicity) e sua contraparte, a não iconicidade (aniconicity). Propõe uma tipologia para a iconicidade na poesia, considerando as dimensões fonéticas, sintáticas, de quebra de linha (enjambement), performativa, rítmica, retórica e gráfica.

Com essa investida, pretende demonstrar que a aplicação da teoria da enunciação e do modelo semiótico de integração conceptual na análise de textos literários traz avanços para a Teoria da Literatura, mas que as Ciências Cognitivas seriam beneficiadas ao se tornarem mais atentas a aspectos da cognição humana que manifestam a natureza cultural da espécie, as nossas experiências estéticas da expressividade literária.

Dessa forma, essa articulação é profícua tanto para os estudos literários 
quanto para os estudos cognitivos, desde que seja mantida uma coerência entre as premissas filosóficas, teóricas e metodológicas. Isso porque a linguagem literária não é deiticamente emoldurada no tempo e espaço, e a intenção não é elaborar uma representação descritiva de uma situação pragmática, mas sim considerar a dimensão da imaginação e da "ingenuidade expressiva" (p. 426). Por um lado, essa característica torna a literatura um caso interessante para a análise semiótica. Por outro lado, os estudos cognitivos podem oferecer vantagens metodológicas e epistemológicas para os estudos literários na medida em que propiciam o entendimento de que o objeto de estudo da literatura revela opções únicas em circunstâncias de produção muito particulares como indicativo de processos universais de construção de sentidos.

Por não se prender a uma descrição do estado de coisas em um fenomundo, a literatura tem seu foco nos espaços de referência e de predicação. Nesse sentido, é um "jogo de linguagem" singular: os participantes compartilham um momento de preocupação com uma não realidade, e as representações são configuradas em um espaço-base semiótico peculiarmente livre de restrições situacionais. Brandt ressalta a necessidade de levar em conta a existência de universais cognitivos e a relevância ontológica da enunciação de proposições inusitadas nos estudos sobre os processos cognitivos da produção literária.

Credito a essa empreitada uma grande inovação, no sentido de criar um novo modelo para análise cognitiva de textos literários. A partir do modelo semiótico de integração conceptual e de premissas da poética cognitiva, Line Brandt desenvolve uma proposta que busca obter uma análise de textos literários que seja validada pelos campos de conhecimento envolvidos - a literatura e a semiótica cognitiva.

Dada a natureza semiótica e pragmaticamente orientada do modelo teórico, é necessário levar-se em conta que toda enunciação sempre acontece na comunicação, como no espaço semiótico base, em que reconhecemos a existência da interação entre EU e TU. Como há discurso, há atenção compartilhada entre um enunciador e um enunciatário. Na produção de sentidos em texto literários, porém, há uma especificidade: o leitor está preparado para suspender a identificação pragmática das vozes dos interactantes e considerar um "estruturador do discurso", uma agência intencional que seja responsável pelo conteúdo dos enunciados em jogo.

Dessa forma, há um encaixamento do espaço-base do narrador na matriz da enunciação (autoral), sem se preocupar com uma autenticidade empírica da identificação dos interactantes, como acontece no discurso pragmático (não literário). O narrador, um agentivo subjetivo intencional, é o responsável por 
enquadrar, emoldurar (to frame) o espaço da estória em curso. Ele determina o conteúdo, o clima e a veridicção (verediction) dos enunciados. O espaço do narrador é uma criação anômala, um artefato literário em si mesmo e sobre si mesmo. Assim, a subjetividade é uma precondição para qualquer enunciado proposicional (BRANDT, 2013, p.470).

A semioticista conclui que é possível discernir a dimensão estética da poética cognitiva ao reconhecer o que está na base (grounding) da textualidade em padrões intersubjetivos da cognição. Sugere um projeto para o futuro no campo da poética cognitiva em que se reconheça uma estética cognitiva das produções literárias. Assim, seria criada, no campo da poética cognitiva, uma poética genuína (BRANDT, 2013, p. 497).

Os pesquisadores interessados em estudar a (inter)subjetividade no processo de interação discursiva, a enunciação fictiva e a enunciação poética à luz da teoria da integração conceptual na perspectiva semiótica, têm, em The Communicative Mind, uma referência segura para o seu trabalho. Ao criar seu próprio percurso teórico e metodológico, Line Brandt realiza, nas referências que faz a outros quadros teóricos, longas e cuidadosas revisitações, retomando e descrevendo princípios, premissas e abordagens metodológicas. Isso porque implementa uma integração interdisciplinar de teorias e métodos para desvelar as implicações da "presença do homem na linguagem”, como preconizou Benveniste.

Referências

BENVENISTE, Émile. Problems in general linguistics. Tradução de M. E. Meek. Coral Gables: University of Miami Press, 1971. (Miami Linguistics Series, 8). Título original: Problèmes de linguistique générale. Original publicado em 1966.

BRANDT, Line. The communicative mind: a linguistic exploration of conceptual integration and meaning construction. Newcastle upon Tyne: Cambridge Scholars, 2013. $636 \mathrm{p}$.

BRANDT, Line; BRANDT, Per Aage. Cognitive poetics and imagery. European Journal of English Studies, v. 9, n. 2, p. 117-130, Aug. 2005.

BRANDT, Per Aage. From Gesture to Theatricality - On Enunciation and the 
Art of Being Visible. In: Spaces, domains, and meaning: essays in Cognitive Semiotics. Bern: Peter Lang, 2004. p. 219-243.

FAUCONNIER, Gilles. Mental spaces: aspects of meaning construction in natural language. New York: Cambridge University Press, 1994.

FAUCONNIER, Gilles; TURNER, Mark. The way we think: conceptual blending and the mind's hidden complexities. New York: Basic Books, 2002.

LAKOFF, George; JOHNSON, Mark. Philosophy in the flesh: the embodied mind and its challenge to western thought. New York: Basic Books, 1999.

LANGACKER, Ronald. Virtual reality. Studies in the Linguistic Sciences, v. 29, n. 2, p. 77-103, 1999.

PASCUAL, Esther. Fictive interaction within the sentence: a communicative type of fictivity in grammar. Cognitive Linguistics, v. 17, n. 2, p. 245-267, 2006.

TALMY, Leonard. Toward a cognitive semantics. Cambridge, MA: MIT Press, 2000. 2 v. 